\title{
A formação dos profissionais educadores ambientais e a universidade: trajetórias dos cursos de especialização no contexto brasileiro
}

\section{The university and environmental education professionals learning: paths of the specialization courses in the Brazilian context}

\author{
Angélica Góis Müller Morales*
}

\begin{abstract}
RESUMO
A universidade como centro de investigação, apresenta-se como um núcleo importante para a formação em educação ambiental, principalmente na (re) organização e no diálogo dos saberes com o intuito de aproximar-se dos problemas socioambientais da sociedade. Por sua vez, a pós-graduação, percebida como um centro de produção de conhecimento mais aberto à incorporação interdisciplinar da dimensão ambiental, constitui-se uma das principais vias de acesso à educação ambiental, principalmente pela oferta de novos cursos de "lato sensu", do tipo especialização. Destarte, este artigo tem o propósito de tecer discussões acerca da instituição universitária, no sentido de debater sua função e refletir sobre seu papel na formação em educação ambiental, direcionado principalmente aos cursos de especialização, com o intuito de analisá-los e compreendê-los. Desta forma, com base em um mapeamento dos cursos de especialização em educação ambiental no contexto brasileiro, percebe-se que há um número significativo de profissionais de diversas áreas de conhecimento que buscam a oportunidade de aprofundar e consolidar sua prática profissional, bem como de uma discussão mais ampla entre sociedade e natureza.

Palavras-chave: cursos de especialização; profissionais em educação ambiental; universidade.

* Doutora do Programa Interdisciplinar em Meio Ambiente e Desenvolvimento pela Universidade Federal do Paraná (UFPR). Mestra em Educação Ambiental pela Fundação Universidade Federal de Rio Grande (FURG) e licenciada em Ciências Biológicas pela Universidade Estadual Paulista (UNESP). Docente da Universidade Estadual de Ponta Grossa - UEPG. Bolsista da CAPES. E-mail: angelicagoismorales@ig.com.br
\end{abstract}




\begin{abstract}
The university, considered as a place of scientific investigation, is an important center for environmental education, particularly due to its ability of (re)organizing knowledge with the purpose of getting more involved with the socio-environmental problems of our society. In that sense, extension courses are acknowledged to be a more open knowledge production center to the incorporation of the interdisciplinary dimension of environmental issues. It is one of the major channels that provide access to environmental education, especially due to the provision of new "lato sensu" (extension), specialization. This paper's objective is to discuss university and its role in developing environmental education, with a special focus on extension courses (specialization), which will be analyzed in order to be understood. This way, from diagnosis of the environmental courses of specialization in Brazil, we notice that there is a significant number of professionals, of many different knowledge, who look for the opportunity to improve and consolidate their carriers, acquiring additional knowledge while they investigate the relationship that exists between our society and nature.

Keywords: extension courses (specialization); environmental education professionals; university.
\end{abstract}

\title{
Introdução: primeiras indagações
}

A crise do conhecimento científico exige um novo papel da universidade, que é convocada a construir uma racionalidade que induza a transformação de paradigmas científicos tradicionais e a promoção de novos conhecimentos e integração de diferentes saberes, com a participação da sociedade.

Para tal exigência, necessita-se problematizar a própria organização do pensamento e da instituição universitária da necessidade da constante modificação. A este encontro, Morin (2002) traz a necessidade de se pensar a reforma universitária como reforma de pensamento, no sentido de formar cidadãos capazes de enfrentar os problemas do seu tempo. Assim, não se pode reformar só a instituição se as mentes não forem também reformadas.

A universidade, como instituição de investigação e centro de educação técnica e superior, tem papel essencial na reconfiguração de mundo e, portanto, deve assumir a responsabilidade maior no processo de produção e incorporação da dimensão ambiental nos sistemas de educação e formação profissional, bem como propiciar, aos profissionais educadores ambientais, fundamentos teóricopráticos indispensáveis para que os mesmos possam compreender, analisar, 
refletir e reorientar seu fazer profissional numa perspectiva ambiental. Ao buscar assumir este papel, algumas indagações vêm à tona: De que forma a educação ambiental está adentrando no ensino superior? No contexto brasileiro, como se configura a educação ambiental nos cursos de especialização?

Para tais questionamentos, este artigo, parte da pesquisa de doutorado da pesquisadora, buscou trazer discussões acerca da instituição universitária, no sentido de refletir seu papel na formação em educação ambiental, diante de um inventário dos cursos de especialização no contexto brasileiro, que vem configurando um núcleo de formação importante para os profissionais educadores ambientais.

\section{A formação em educação ambiental: trajetórias e reflexões na universidade}

[...] formação ambiental é pertinente para compreender a transformação da realidade causada pela problemática do desenvolvimento. A formação implica um processo mais orgânico e reflexivo de reorganização do saber e da sociedade na construção de novas capacidades para compreender e intervir na transformação do mundo (LEFF, 2001, p. 254).

A universidade é um dos espaços de formação que busca problematizar e atender a novas demandas sociais e profissionais que requer o mercado de trabalho, o que exige de si mesma uma redefinição e adequação dos processos de formação. Desta forma, pensar na formação profissional, direcionada ao campo da educação ambiental, exige das instituições universitárias a tentativa de superar o paradigma dominante e as fragilidades impostas pelo mesmo.

A necessidade e urgência de formação de educadores ambientais decorreram desde as recomendações da Conferência de Tbilisi, em que delinearam algumas diretrizes em que a educação ambiental, nos espaços universitários deveria: romper com os modelos tradicionais de educação ao aceitar a interdisciplinaridade para a solução de problemas sócioambientais; desenvolver materiais pedagógicos locais e estabelecer cooperações locais, nacionais e internacionais, bem como incluir no programa de formação de professores a educação ambiental; ajudar docentes dos centros de formação de professores na área de educação ambiental e facilitar, aos futuros professores, formação ambiental apropriada ao meio urbano ou rural (UNESCO, 1994). 
Direcionado ao ensino superior, destacam-se os Seminários sobre "Universidade e Meio Ambiente" ocorridos no Brasil entre os anos 1986 e 1992, que contribuíram na apreciação do papel da universidade como espaço de vinculação com a temática ambiental. Frente às análises destes seminários, embora se evidencie uma sequência de aprofundamento na temática, percebe-se que a relação da universidade com as questões ambientais se dá, ainda, de forma limitada.

A estrutura do ensino superior, organizada em departamentos, divisões institucionais que se transformaram em territórios de poder e afirmações de identidade intelectual, tende a valorizar as especificidades, o que, muitas vezes, faz com que a interdisciplinaridade não ocorra. Contudo, estes debates produzem uma resignificação do ambiental nos diferentes saberes de cada campo, o que faz repensar a complexidade da questão ambiental diante da postura interdisciplinar, bem como estabelecer uma ponte entre o saber científico e o saber popular, ao encontro de um diálogo de saberes que busque compreender a realidade na promoção da sustentabilidade (LEFF, 2001).

Em decorrência desses primeiros seminários nacionais sobre meio ambiente e universidade, em 1990, ocorre o I Curso Latino-Americano de Especialização em Educação Ambiental ofertado pelo PNUMA, IBAMA e Universidade Federal do Mato Grosso ${ }^{1}$. Assim, é a partir de 1990 que várias universidades, inspiradas nas recomendações e diretrizes traçadas nestes seminários, cunharam estratégias para incorporar a dimensão ambiental. Dentre as tentativas em romper com os paradigmas tradicionais que aprisionam o ensino superior, criaram disciplinas optativas e comissões interdepartamentais ou programas e cursos interdisciplinares, vinculados à reitoria para conseguir certa independência dos departamentos disciplinares e também implementaram cursos de pós-graduação lato e stricto-sensu ${ }^{2}$ na área de educação e meio ambiente.

Com base nessas aberturas, vale evidenciar que, com o ganho de aportes legais, teóricos e metodológicos, a década de 90 cooperou para a emergência de muitos cursos de Pós-Graduação, desde Especialização até Mestrado e Doutorado. Entre muitos, destaca-se o curso de Mestrado e Doutorado em Educação Ambiental da Fundação Universidade Federal de Rio Grande (FURG-RS), o Programa Interdisciplinar do Doutorado em Meio Ambiente e Desenvolvimento e a Especialização em Educação, Meio Ambiente e Desenvolvimento da Univer-

1. Curso criado em parceria com o Conselho Nacional de Desenvolvimento Científico e Tecnológico (CNPq) e da Coordenação de Aperfeiçoamento de Pessoal de Nível Superior (CAPES). O curso foi reeditado até meados de 1994 e oferecido para funcionários do IBAMA, MEC e instituição universitária.

2. Para efeito de esclarecimento, os cursos de lato-sensu são cursos de especialização e aperfeiçoamento, enquanto os de stricto-sensu incluem os cursos de mestrado e doutorado, com objetivos mais amplos e aprofundados da formação científica. 
sidade Federal do Paraná (UFPR), entre muitos outros que vêm se consolidando no espaço universitário.

Frente a esses novos espaços no ensino superior de discussão relacionados à educação ambiental, ressaltam-se os Encontros de Pesquisa em Educação Ambiental (EPEA), Encontros Nacionais da Associação Nacional de Pós-Graduação e Pesquisa em Ambiente e Sociedade (ANPPAS) e Encontros Nacionais da Associação Nacional de Pós-Graduação em Educação (ANPED) como espaços de debate reflexivo no meio acadêmico, composto por (re)construções teóricas e metodológicas e de troca e avaliação de trabalhos de pesquisa em educação ambiental de diferentes grupos que desenvolvem pesquisas no Brasil, seja por meio de programas de graduação, pós-graduação ou outros espaços institucionais.

Desde então, iniciativas vêm firmando-se frente às questões sócioambientais nas universidades, assumindo também a responsabilidade maior no processo de produção e incorporação ambiental nos sistemas de educação e formação profissional, principalmente em cursos de pós-graduação.

Destacando-se a pesquisa interdisciplinar, a intervenção ambiental adota melhor configuração em cursos de pós-graduação por terem um caráter multi e interdisciplinar, além de que, como afirma Heemann (2001, p. 15), "o processo de formação do pesquisador [...] passa por um entendimento sobre a finalidade primordial da pós-graduação". Assim, observa-se que a formação profissional de educação ambiental se dá principalmente em nível superior, e é na pósgraduação que está ocorrendo esta inserção ambiental com mais intensidade. Como constata Carvalho (2001, p. 167), "a temática ambiental na educação ambiental tem encontrado na pós-graduação sua porta de entrada".

No Brasil, as experiências relacionadas à formação de especialistas em educação ambiental se dão principalmente por meio de programas de pósgraduação lato-sensu e stricto-sensu em educação ambiental propriamente dita, e/ou por meio de temática afim e/ou ainda por área de concentração que esteja vinculada à educação ambiental. "Esse reconhecimento passa pela conjugação da aquisição de um saber, da titulação formal e da rede de relações que geralmente se constrói nessas esferas", como afirma Carvalho (2001, p. 165).

Como se percebe, é crescente a oferta de $\operatorname{cursos}^{3}$ que se consolidam na formação e na qualificação de profissionais educadores ambientais. Contudo, vale ressaltar que, entre esta crescente abertura de cursos na área ambiental, certamente pode-se encontrar alguns programas que se lançam para atender a

3. Em 2001, Carvalho identificou 45 cursos (desde pós-graduação aos cursos de extensão) de formação de especialistas em Meio Ambiente e Educação Ambiental no cenário brasileiro. Contudo, como a oferta de cursos só aumenta, fica muito difícil quantificá-los com precisão, mas, de acordo com levantamento prévio e agregando os dados da RUPEA, pode-se estimar que há em torno de 70 cursos direcionados à formação ambiental de profissionais na área da pós-graduação. 
demanda do mercado, como oportunidade de momento, vindo ao encontro de um modismo apenas, cujo caráter e conteúdos ambientais, muitas vezes, não são reformulados para incorporar a dimensão ambiental de forma crítica e reflexiva, com base em pensamento complexo e postura interdisciplinar.

Não obstante, a incorporação da educação ambiental em programas de cursos de pós-graduação ganha legitimidade, embora lentamente, aos poucos busca introduzir novas percepções, atitudes e possíveis fundamentos teóricometodológicos. A este encontro, não se pode deixar de enfatizar que o tema educação ambiental está presente desde 1984 na produção de dissertações e teses, com um total estimado de 256 dissertações, 40 teses e 1 tese de livre docência (REIGOTA, 2002).

Considera-se que são perceptíveis as iniciativas singulares introduzidas no cenário da pós-graduação, como as próprias produções que adentram no mundo científico, o que sugere uma ampla e maior compreensão da educação ambiental nas universidades, agências de fomento e na própria definição de políticas públicas. Nesta caminhada por uma educação ambiental que estimule o repensar das bases do conhecimento e o desenvolvimento da sociedade, os cursos de pós-graduação lato-sensu, do tipo especialização, são iniciativas bastante interessantes em vários programas de pós-graduação e departamentos, contribuindo na inserção da dimensão ambiental no ensino superior, em perspectiva interdisciplinar e também em reflexão sobre a incorporação da dimensão ambiental no ensino superior.

Para tanto, dedicou-se a um inventário mais detalhado do universo da especialização no Brasil, com a intenção de que este levantamento preliminar possa dar subsídios ilustrativos e interpretativos que vem compondo este setor no cenário do ensino superior frente à formação em educação ambiental.

\section{O contexto brasileiro dos Cursos de Especialização em Educação Ambiental: um inventário}

Os cursos de pós-graduação lato-sensu, do tipo especialização ${ }^{4}$, que trabalham com a dimensão ambiental no país, constituem um marco relevante, pois, a partir deles, novos questionamentos, pressupostos e conceitos teórico-metodológicos são introduzidos, de forma ainda lenta, na educação superior e, consequentemente, na formação de profissionais de diversas áreas de conhecimento.

4. Cabe esclarecer que cursos de especialização apresentam uma carga horária mínima de 360 horas/aula e um maior aprofundamento dos conhecimentos profissionais ou científicos por meio de processo de formação na pesquisa para a produção de conhecimento. 
A dimensão ambiental, questionada e desenvolvida principalmente pelos movimentos ambientalistas, organizações não governamentais e governamentais, ao ser incorporada nos discursos oficiais, tais como desenvolvimento sustentável, agenda 21, políticas ambientais, entre outros conceitos e problemáticas sócioambientais, gerou um movimento no mercado, que se abriu para um mundo de empregos e de profissionalização no campo ambiental, bem como para a educação ambiental, como destaca Gutiérrez-Perez (2005), ao evidenciar o profissional do setor ambiental como novo campo de ação e de profissionalização sócioambiental.

Desse modo, a área ambiental adentrou no cenário da universidade como forma de atender esse mercado, porém com aspirações diferentes, que implicam em problematizações contrárias à sociedade tradicional e hegemônica, trazendo à tona uma crítica contundente ao pensamento cartesiano e reducionista.

Frente a essas tensões, as especializações direcionadas à temática educação ambiental surgem crescentemente, de tal forma que, mesmo ainda vagarosamente, parecem fomentar um espaço de legitimação da situação profissional do educador ambiental, que, por sua vez, assume uma das principais vias de acesso na universidade. Isto talvez ocorra por não ter nenhuma graduação relacionada à educação ambiental e por ter apenas um curso de pós-graduação stricto-sensu (mestrado e doutorado - FURG) em nível nacional. Assim, no contexto brasileiro, cursos expandem-se na área da educação ambiental, de acordo com os caminhos da institucionalização profissional e também com os desafios postos pelos problemas que afligem toda sociedade, e, por isso, torna-se importante estudá-los, compreendê-los, justificá-los e analisá-los.

Diante do inventário realizado, observa-se que, com o número de cursos de especialização encontrados, há um número significativo de profissionais das diversas áreas de conhecimento que buscam, na especialização, conhecimentos teórico-práticos, a fim de validar suas ações e avançar no debate e na produção de saberes relevantes e necessários aos problemas sócioambientais presentes na sociedade contemporânea.

O inventário realizado nos cursos de especialização, como diagnóstico e mapeamento inacabado e sem nenhuma pretensão de ser conclusivo e esgotálo, foi configurado mediante buscas pela internet e por contatos, pela lista de discussão das redes de educação ambiental, com pesquisadores e educadores ambientais que trabalham em cursos de pós-graduação. Ressalta-se que, durante este diagnóstico, teve-se acesso ao Relatório do Projeto RUPEA (Rede Universitária de Programas de EA para Sociedades Sustentáveis) e MEC, sobre o mapeamento da educação ambiental em Instituições Brasileiras de Educação Superior (2005), que serviram de subsídios e vieram ao encontro dos objetivos propostos pelo inventário desta pesquisa e, por conseguinte, da atualização dos 
dados obtidos preliminarmente pela RUPEA.

Ao realizar este levantamento no segundo semestre de 2006, optou-se pela modalidade presencial, já que, atualmente, muitos cursos apresentam modalidade à distância ou ambas (semipresencial) ${ }^{5}$, bem como por cursos direcionados à temática educação ambiental de instituições tanto privadas como públicas. Todavia, o interesse maior foi verificar as Instituições de Ensino Superior (IES) estaduais e/ou federais, como espaços representativos e significativos em nossa sociedade. Foram mapeados 22 cursos de especialização em Educação Ambiental, que se situam nas regiões norte, nordeste, centro-oeste, sudeste e sul, compondo as cinco grandes regiões que constituem a divisão espacial do Brasil, como pode ser verificado no Quadro 1.

Diante dos cursos de especialização mapeados, observa-se que, em sua maioria, apresentam criação e implementação na década atual. É perceptível, a partir de 2001, um número maior, contabilizando-se 14 cursos neste período, e na sua grande maioria em andamento. Entretanto, a década de 90 também tem um número considerável, embora menor, pois traz os reflexos dos seminários sobre universidade e meio ambiente e da Conferência Rio-92, além de muitas iniciativas de Organizações Governamentais e Não-Governamentais frente às questões sócioambientais neste mesmo período.

Sob esse prisma de reflexos, percebe-se que as IES, na inserção da dimensão da educação ambiental, buscam, por meio da especialização, articulação e flexibilidade de tal modo que permita certa liberdade em sua organização estrutural. Assim, percebe-se que, os cursos mais recentes, geralmente, estão vinculados em Pró-Reitorias de Pesquisa e Pós-Graduação, como as instituições CEFET, FSA, UFPR e/ou núcleos de pesquisas em educação ambiental, como demonstra CUML, NIMAD/UFPR, UEPA, ou ainda, em número menor, núcleos de pesquisa ligados a diversos departamentos, como UFG e UERJ.

No entanto, na década de 90, apresentam-se cursos de especialização vinculados mais aos departamentos, os quais se destacam, principalmente, departamentos de Pós-Graduação em Educação. Justifica esta incidência acadêmica, porque a educação ambiental é vista como a própria educação; e também vinculado aos departamentos de Geografia, Ciências Biológicas e áreas afins, que mantêm forte ligação com as ciências naturais.

5. A estas modalidades, cabe destacar a Fundação Universitária Iberoamericana, sediada em Florianópolis, pela coordenação de Nana Mini-Medina, que, a partir de 2006, iniciou cursos de especialização em Educação Ambiental com parcerias de várias instituições. 


\begin{tabular}{|c|c|c|c|c|c|c|c|c|c|c|c|}
\hline 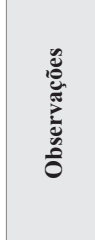 & 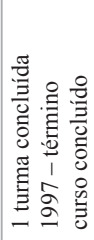 & 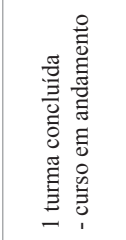 & 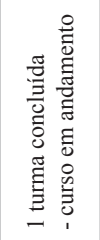 & 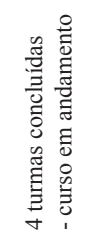 & 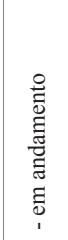 & 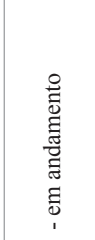 & 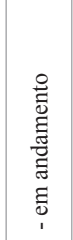 & 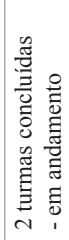 & 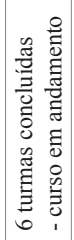 & 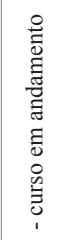 & 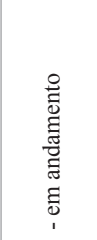 \\
\hline 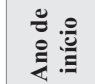 & よ & ষ্ণ & ث্ণ & ๕ి & ষ্ণ & $\stackrel{\partial}{\sigma}$ & ڤి̊ & ڤి̊ & ণิ & ষ্ণ & $\stackrel{\infty}{\stackrel{\sigma}{\sigma}}$ \\
\hline בَّ & : & ஓ & \& & $\tilde{\sim}$ & $\stackrel{8}{\infty}$ & $\stackrel{n}{n}$ & $\overrightarrow{\text { m }}$ & ळ) & $\stackrel{8}{\infty}$ & : & $\underset{m}{8}$ \\
\hline 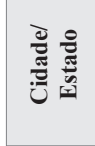 & 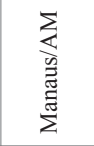 & 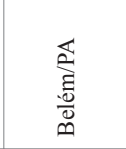 & 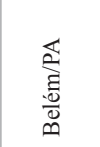 & 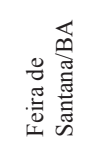 & 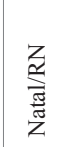 & 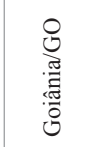 & 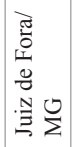 & 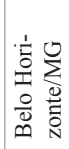 & 岱 & 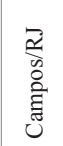 & 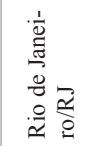 \\
\hline 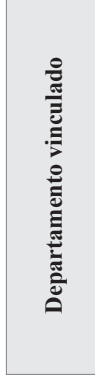 & 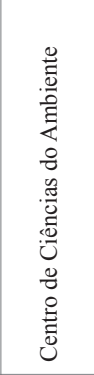 & 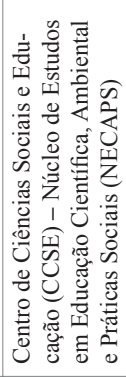 & 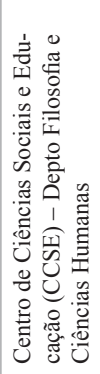 & 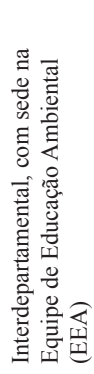 & 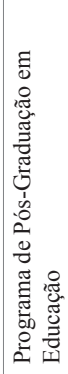 & 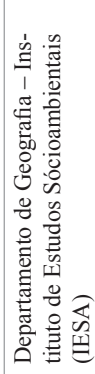 & 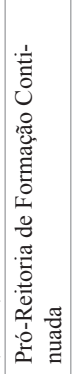 & 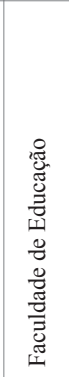 & 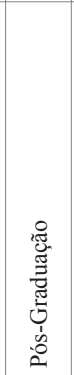 & 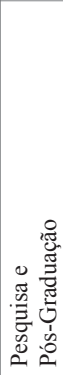 & 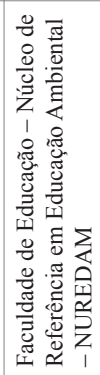 \\
\hline 匏 & 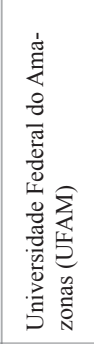 & 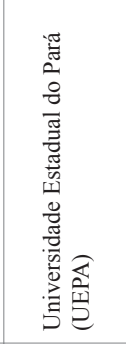 & 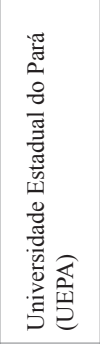 & 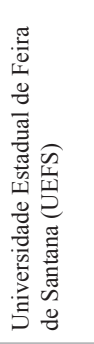 & 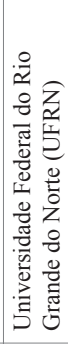 & 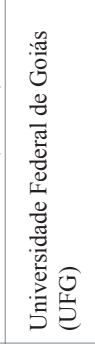 & 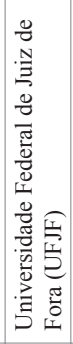 & 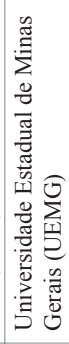 & 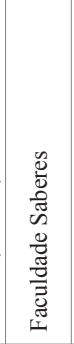 & 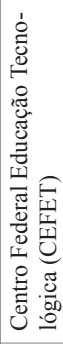 & 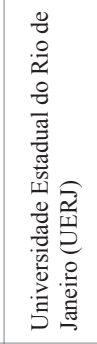 \\
\hline 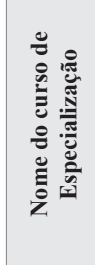 & 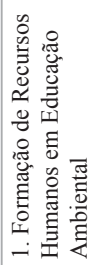 & 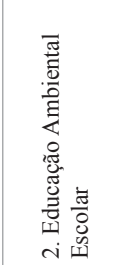 & 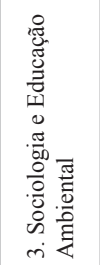 & 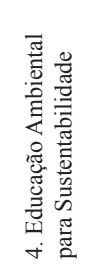 & 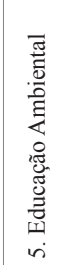 & 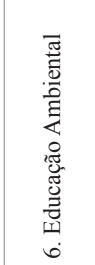 & 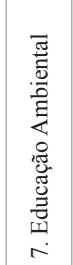 & 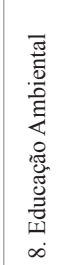 & 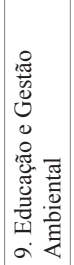 & 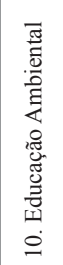 & 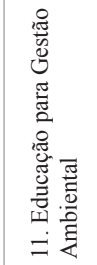 \\
\hline
\end{tabular}




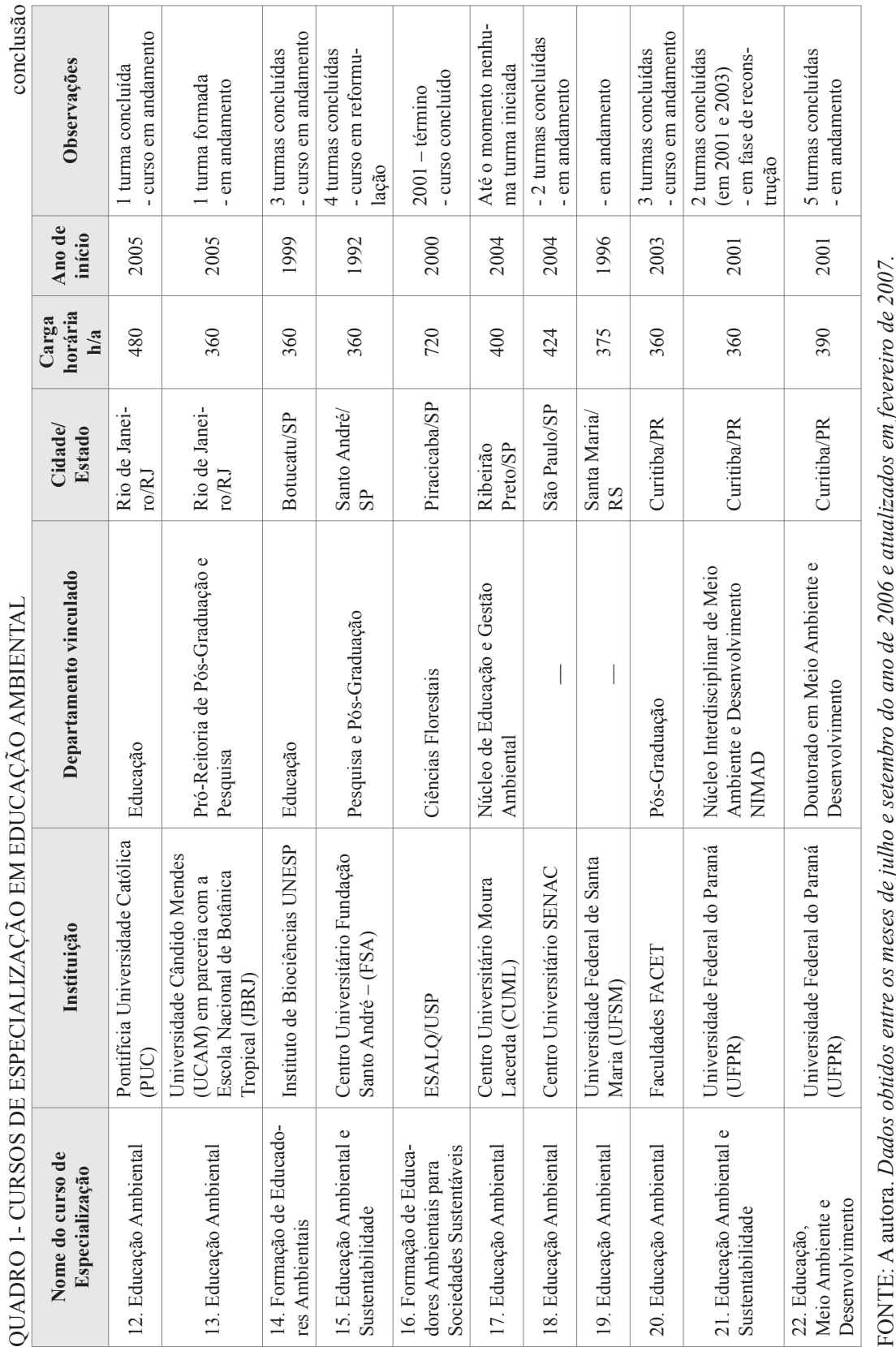


Assim, pela questão ambiental apresentar várias identidades, em campo heterogêneo, plural e multirreferencial, é possível encontrar cursos vinculados de forma organizacional, estrutural e hierárquica diferenciados, proporcionando contornos e desenhos específicos e particulares de acordo com os regulamentos e bases estruturais de cada instituição universitária. Frente a essas (re)organizações, verifica-se que a especialização pode ser um espaço positivo para as discussões da própria reformulação estrutural dentro da Universidade, pois, ao buscar articulação disciplinar que permita integrar as diversas áreas de conhecimento, pode tentar romper com a estrutura departamental hegemônica e obsoleta que ainda prevalece.

Dessa forma, pode ainda contribuir nas decisões políticas das instituições no sentido de abrir espaços necessários à incorporação da dimensão ambiental, que busque a relação entre as ciências naturais e sociais. A esta apreciação, pode-se salientar o curso "Sociologia e Educação Ambiental", encontrado no inventário, que tenta atender esta articulação entre as áreas de conhecimento, mostrando que as ciências humanas, ainda de forma tímida, estão se voltando às questões sócioambientais de forma a problematizar o ambiental em sua área do saber.

Dos 22 cursos de especialização, encontra-se, em sua maioria, no título, o termo "sustentabilidade" ou "sociedades sustentáveis". Isto implica que o debate em torno da sustentabilidade e/ou desenvolvimento sustentável é uma das orientações e diretrizes dos cursos, acompanhando a formação dos educadores ambientais. Contudo, espera-se que, neste processo de formação, possa exercer momentos de reflexão crítica para analisar, discutir, contestar e identificar o campo de disputas que permeia a apropriação do significado de sustentabilidade.

Face aos objetivos encontrados nesses cursos, embora, alguns de modo vago ou muito amplo, pode-se chegar aos focos centrais: a formação de educadores ambientais para atuarem de forma reflexiva e crítica nos processos sócioambientais e educativos; e a compreensão da gestão ambiental para possível aplicação da política ambiental na região. Assim, a educação e a gestão ambiental, em alguns cursos, estão totalmente interligadas e fortemente enfocadas, sendo que, em outros, a formação de educadores ambientais está direcionada a sustentabilidade. Entretanto, o que ainda predomina é a formação de educadores ambientais, com ênfase em postura interdisciplinar e focada para a qualificação profissional. Tais dados vêm ao encontro dos resultados do mapeamento da RUPEA (2005), que encontrou dois focos explicitados no curso de especialização: a formação de educadores ambientais e de gestores ambientais.

Ao correlacionar os objetivos dos cursos, todos são oferecidos a qualquer profissional de nível superior, ou seja, direcionados aos profissionais graduados, 
oriundos de todas as áreas de conhecimento, o que implica uma coerência com a discussão que permeia o campo da educação ambiental. Todavia, alguns, além de terem esse mesmo público-alvo, também enfatizam professores da rede pública de ensino, como o caso do curso de especialização "Educação Ambiental Escolar" da UEPA, que tem um direcionamento mais específico, voltado à educação ambiental formal.

Com essas várias identidades profissionais que compõem o universo das especializações, as disciplinas também configuram um mosaico diversificado nos currículos dos cursos. Neste enfoque disciplinar, vale ressaltar que, ao se ter acesso às disciplinas dos cursos mapeados, notou-se que a interdisciplinaridade, embora se apresente nos objetivos, diante de postura ou caráter aliado aos cursos, não se apresenta de forma explícita como temática disciplinar. Entre as disciplinas, pode-se destacar algumas, como: Ecoturismo, Biologia da Conservação e Bases Filosóficas da EA (relacionadas aos aspectos da epistemologia, complexidade e ética) que estão presentes nos currículos, pois não é um núcleo de disciplinas comum nos cursos, assim como outras disciplinas encontradas, como: Antropologia, Sociologia, Comunicação e Meio Ambiente, Tecnologias, EA em empresas, Saúde Ambiental, Perspectiva Interdisciplinar e Economia Ambiental, que se apresentam em número bem reduzido se comparado ao total dos cursos.

Por sua vez, as disciplinas mais presentes nesses cursos estão direcionadas ao universo da educação e gestão ambiental, sendo que, em todos os programas dos cursos, a Legislação Ambiental e Ecologia estavam contempladas, bem como os Fundamentos da EA, como aspectos históricos, teóricos e metodológicos e Noções de Gestão Ambiental. Aqui, corrobora-se com Brugger (1994, p. 44) ao destacar que alguns cursos de especialização continuam tendo "como base filosófica uma visão instrumental de mundo", e prova disto ainda é a presença maior de temas ecológicos com tendência naturalista e também de temas instrumentais como gestão e administração.

Como se observa, esses cursos ainda têm, nos seus currículos, tendência maior aos aspectos e temas ambientais, decorrentes da ciência da natureza, se comparados com as ciências da sociedade, que se apresentam em número reduzido. Porém, nota-se que os cursos criados mais recentemente, a partir de 2001, por exemplo, trazem variedade de disciplinas que tentam articular o debate entre as ciências naturais e sociais, destacando-se a temática da relação natureza e sociedade, referenciada em muitos dos cursos.

Os cursos mapeados apresentam periodicidade regular, e são, em sua maioria, ofertados anualmente, ou conforme o número de alunos suficientes para sua viabilização. Contudo, há alguns cursos que foram ofertados e que hoje não estão mais em funcionamento. Existe flexibilidade muito grande 
nesses cursos, que vai desde abertura, reformulação, até o fechamento, pois a especialização, nas universidades, é financiada, em sua maior parte, pela taxa paga pelos próprios alunos.

Não obstante, verifica-se um número considerável de turmas formadas nesses cursos de especialização frente a todo processo recente de incorporação ambiental nas universidades. Assim, percebe-se que os cursos de especialização criam espaços de aprendizagem, de experiência científica, de investigação e de problematização sobre as questões sócioambientais, políticas e sócioculturais, contribuindo na formação de recursos humanos para os diversos setores da sociedade, bem como no desenvolvimento da ambientalização no ensino superior, que necessita de formulações de políticas públicas que facilitema inserção da EA nos cursos das instituições universitárias.

\section{Considerações: novas indagações}

Embora a dimensão ambiental não tenha, ainda, alcançada internalização no âmbito do ensino superior, a especialização é mediadora não só das discussões para que isto ocorra com mais efetividade e sistematização, mas também na experiência profissional de vários educadores ambientais, que encontram, nesses cursos, oportunidade de aprofundar e consolidar sua prática profissional, bem como na problematização da discussão mais ampla entre sociedade e natureza, que contribui no delineamento de uma possível epistemologia ambiental. No entanto, ficam algumas questões instigantes, tais como: o que motiva um conjunto de profissionais a ingressar em programa de formação acadêmica na área de EA, como as especializações? Qual sujeito educador ambiental a especialização está formando?

Frente ao exposto, percebe-se que a educação ambiental nas vias da pósgraduação busca seu espaço científico. Portanto, como este campo se fundamenta em paradigma nada tradicional, torna-se difícil, muitas vezes, sua entrada no cenário superior, pois, ao apresentar-se como crítica ambiental ao pensamento hegemônico, ainda não se conseguiu bases epistemológicas para fazer com que a academia possa atender essa exigência de maneira mais efetiva para além da inserção de uma disciplina ou programa de educação ambiental (TRISTÃO, 2004; CARVALHO, 2001; TOZONI-REIS, 2004).

Dessa forma, a educação ambiental brasileira parece que é incorporada aos cursos de pós-graduação em que as atividades científicas, produzidas neste setor, encontram-se relacionadas, particularmente, com os próprios sujeitos, os 
"sujeitos ecológicos", que buscam e criam espaços para a produção do conhecimento na área da educação ambiental, contribuindo diretamente na caminhada da problematização e crítica ambiental frente ao pensamento cartesiano, fragmentado e reducionista que ainda impera. Portanto, para formar profissionais de educação ambiental, abertos à reflexão, à transformação e à crítica diante de conhecimentos fragmentados e disciplinares, se faz necessário a superação de formas de alienação, a partir da construção de um saber ambiental que se contrapõe à racionalidade instrumental e à valorização de atitudes juntamente com a articulação dos princípios essenciais a essa formação.

A essas considerações, a inserção da dimensão ambiental no meio universitário passa por processo contínuo de reformulação do conhecimento ambiental, o que implica a valoração e a articulação interdisciplinar dos saberes práticos e acadêmicos, bem como a própria reformulação da universidade, em suas formas operacionais, para internalizar a complexidade ambiental. Em relação ao desafio e necessidade da transformação estrutural da universidade, Riojas (2003, p. 224228) destaca alguns níveis que devem ser trabalhados no ensino superior para a incorporação da complexidade ambiental. São eles: - nível conceitual-paradigmático, que é o processo de ambientalização e complexificação do conhecimento, relacionando a internalização da dimensão ambiental ao objeto de conhecimento próprio de cada disciplina; - nível pedagógico-didático, direcionado às implicações pedagógicas, didáticas e técnicas de trabalho educativo que promovam o aprender a ver as conexões e a inter-relacionar e ambientalizar o próprio campo de saber com outros e reconhecer a incompletude da área de especialização disciplinar ou profissional em cada caso; e - nível ético-epistemológico, que busca reconsiderar o processo de construção do conhecimento e a política que está por trás deste conhecimento, em função de projeto sócioambiental.

De acordo com esses níveis, a instituição superior pode conseguir um questionamento integral, desde o ponto de vista conceitual, teórico, pedagógico, como também institucional e existencial. Desta forma, a universidade, na tentativa de superar o conhecimento simplificador, por meio da complexidade ambiental, estará contribuindo, concomitantemente, com a formação em educação ambiental que, focada na prática sócioambiental, torna-se transformadora, crítica e reflexiva.

6. Incorpora, aqui, o "sujeito ecológico", desenvolvido por Carvalho (2001, p. 72-75), como aquele sujeito que tem na educação ambiental a sua ação educativa. Um sujeito militante, vanguarda dos movimentos sociais históricos, que ao mesmo tempo é herdeiro de tradições políticas de esquerda e ator no discurso de um novo paradigma político e social. 


\section{REFERÊNCIAS}

BRUGGER, P. Educação ou adestramento ambiental: Santa Catarina: Letras Contemporâneas, 1994.

CARVAlHO, I. C. M. A Invenção ecológica: narrativas e trajetórias da Educação Ambiental no Brasil. Porto Alegre: UFRGS, 2001.

GUTIÉRREZ-PÉREZ, J. Por uma formação dos profissionais baseada em competências de ação. In: SATO, M.; CARVALHO, I. Educação Ambiental: pesquisa e desafios. Porto Alegre: Artmed, 2005. p. 177-211.

HEEMANN, A. A finalidade da pós-graduação. In: Tecnologia, sociedade e meio ambiente. Curitiba: CEFET, 2001, p. 15-20. Publicação do Programa de Pós-Graduação em Tecnologia.

LEFF, E. Saber ambiental: sustentabilidade, racionalidade, complexidade, poder. Rio de Janeiro: Vozes, 2001.

MORIN, E. A cabeça bem-feita: repensar a reforma, reformar o pensamento. Rio de Janeiro: Bertrand, 2002.

REIGOTA, M. El estado del arte de la educación ambiental. Tópicos en Educación Ambiental, México, Universidad de Guadalajara, v. 4, n. 11, p. 49-62, ago. 2002.

RIOJAS, J. A complexidade ambiental na universidade. In: LEFF, E. et al. A complexidade ambiental. São Paulo: Cortez, 2003.

RUPEA. Mapeamento da Educação Ambiental em Instituições Brasileiras de Educação Superior: elementos para discussão sobre políticas públicas. São Carlos: UFSCAR, 2005. Relatório.

TOZONI-REIS; PIRES, M. F. C. Educação ambiental: natureza, razão e história. Campinas-SP: Autores Associados, 2004.

TRISTÃO, M. A educação ambiental na formação de professores: redes de saberes. São Paulo: Annablume, 2004.

UNESCO. Programa Internacional de Educación Ambiental. Estrategias para la formación del profesorado en educación ambiental. Vasco: CENEAN, libros de la Catarara, n. 25, 1994. 